\title{
Synthesis of Indanes by Enantioselective Direct Arylation
}

Metal-Catalyzed Asymmetric Synthesis and Stereoselective

Reactions

\section{Key words}

direct arylation

palladium

desymmetrization

\section{SYNFACT}

Selected examples:

Mechanistic model:<smiles>O=C(O)O[Tl]C1=CCCCC1=Cc1ccccc1</smiles>

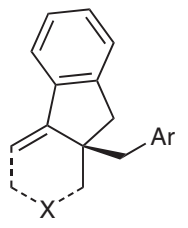

13 examples up to $99 \%$ yield up to $97 \%$ ee

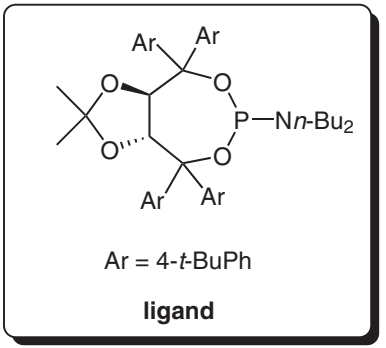

enantioselective direct arylation<smiles>O=C(O)O</smiles><smiles>C1=C2c3ccccc3CC2(Cc2ccccc2)C[13CH2][13CH2][13CH2]1</smiles>

$\mathrm{MeO}$
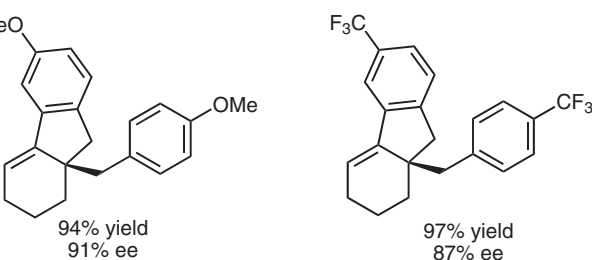

$97 \%$ yield
$87 \%$ ee
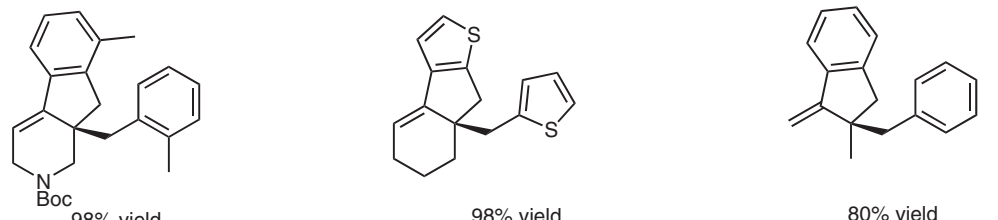

$87 \%$ ee

$98 \%$ yield
$93 \%$ ee

$80 \%$ yield

$45 \%$ ee

Significance: Transition-metal-catalyzed C-H functionalization reactions are becoming increasingly practical; however, highly enantioselective variants are rare (see Review below). The authors have identified a catalytic system which allows for the desymmetrization of enantiotopic aryl $\mathrm{C}-\mathrm{H}$ bonds using a palladium-catalyzed direct arylation.

Review: R. Giri, B.-F. Shi, K. M. Engle, N. Mangel, J.-Q. Yu Chem. Soc. Rev. 2009, 38, 3242-3272.
Comment: The key step in the catalytic cycle is proposed to involve a concerted metalationdeprotonation (CMD) reaction. The use of a chiral monodentate ligand is required to induce enantioselectivity, and bulky taddol-based phosphoramidite ligands were optimal. The reaction is performed at room temperature using $\mathrm{NaHCO}_{3}$ as a base, making the process exceptionally mild. 